\title{
Fuzzy Rule Based Optimization of Multiple Responses in Turning of GFRP Composites
}

\author{
Syed Altaf Hussain ${ }^{1}$, Palani Kumar.K ${ }^{2}$ and Gopala Krishna. $\mathrm{A}^{3}$ \\ ${ }^{1}$ School of Mechanical Engineering, R.G.M College of Engineering and \\ Technology, Nandyal-518501, A. P, India \\ ${ }^{2}$ Department of Mechanical Engineering, Sri Sai Ram Institute of Technology, \\ Chennai-44, T.N, India \\ ${ }^{3}$ Department of Mechanical Engineering, JNTUCE-Kakinada, A.P, India \\ *rgmaltaf1@gmail.com
}

\begin{abstract}
Glass fiber reinforced polymer (GFRP) composites are finding increased applications due to their superior advantages over other engineering materials. This paper presents, the use of Fuzzy logic combined with Taguchi method for the optimization of multiple performance characteristics considering surface roughness, and cutting force. Experiments were planned according to $L_{25}$ orthogonal array in Taguchi's design of experiments. Experiments were performed on an all geared lathe using CBN (Cubic Born Nitride) cutting tool insert. The results reveal that the optimization technique is greatly helpful for simultaneous optimization of multiple quality characteristics i.e., surface roughness $\left(R_{a}\right)$ and cutting force $\left(F_{z}\right)$.
\end{abstract}

Keywords: GFRP composites, Taguchi, Fuzzy logic, Optimization, CBN tool

\section{Introduction}

The users of FRP composites are facing difficulties to machine it, because of delamination, fiber pull out, short tool life, matrix debonding, burning and formation of powder like chips. To minimize the damage in machining, it is important to monitor process variables such as cutting speed, feed, depth of cut etc. In most applications, traditional metal cutting machine tools and techniques are still being used. But machining of FRP composites is different from that of conventional materials because of its inhomogeneity [1]. Past several years, the phenomenon of machining FRP composites has been analyzed by researchers. Experimental studies on traditional machining of Fiber reinforced plastics were first reported by $[2,3]$. Influence of fiber orientation on both the quality of the machined surfaces and tool wear [4]. The machinability of composite materials is influenced by the type of fiber embedded in the composites and more particularly by the mechanical properties. On the other hand, the selection of cutting parameters and the cutting tools are dependent on the type of fiber used in the composites and which is very important in the machining process. The mechanism of material removal during GFRP machining and the type of wear in high-speed steel tools were studied with the help of scanning electron microscope [5]. Studies on machining of polymer composites are carried out and concluded that higher cutting speeds give better surface finish [6]. While machining of GFRP composites, higher cutting speed produce more damage on the machined surface, this is attributed to higher cutting temperature which results in local softening of work material [7]. The influences of cutting parameters on surface roughness in turning glass-fiber reinforced plastics using statistical analysis were studied by [8]. The machinability of GFRP composites indicates the relative ease with which a given material can be machined using appropriate tool and machining 
parameters. Cutting force, cutting power and specific cutting pressure are some of the criteria to evaluate machinability.

Machining studies on carbon fiber reinforced plastics (CFRP) composites were performed and measured cutting forces in both parallel and perpendicular to the fiber orientation using quick stop experiments [2]. Machinability of GFRP by means of different tool materials and geometries were performed and concluded that by proper selection of cutting tool material and geometry, excellent machining of the work piece can be achieved [9]. Analytical and experimental studies were carried out on the orthogonal cutting mechanism of unidirectional graphite/epoxy composites with a diamond tool [10]. A regression model to predict cutting force in terms of rake angle, clearance angle, depth of cut and cutting speed were developed their studies reveal that, apart from fiber orientation, tool geometry has consistently been noted as a critical cutting parameter which influences the cutting force, surface quality and tool wear [11]. Optimization study of surface roughness in turning GFRP tubes manufactured by filament winding and hand lay-up and machined using polycrystalline diamond cutting tool, the optimal cutting parameters were identified to obtain a certain surface roughness ( $R a$ and $R t / R \max )$, corresponding to international dimensional precision (ISO) IT7 and IT8 in the FRP work pieces, using multiple analysis regression (MRA). Additionally, the optimal material removal rates were identified [12]. The application of the Taguchi method combined with fuzzy logic to optimize the machining parameters in machining of GFRP composites with multiple characteristics. A multi-response performance index (MRPI) was used for optimization. The machining parameters viz., work piece (fiber orientation), cutting speed, feed rate, depth of cut and machining time were optimized with consideration of multiple performance characteristics viz., metal removal rate, tool wear, and surface roughness. The results from confirmation runs indicated that the determined optimal combination of machining parameters improved the performance of the machining process [13]. Optimization study on machining of randomly oriented glass fiber reinforced (GFRP) polymer composite rods with different process environment. An expert system based on fuzzy rule based modeling approach combined with Taguchi's robust design philosophy has been adopted to evaluate the optimal process parameters thereby satisfying conflicting requirements of material removal rate (MRR) and surface roughness of the machined composite product. Effectiveness of the proposed model has been illustrated in this reporting [14]. Machining studies have performed on FRP composite tubes of different fiber orientation with PCD cutting tool and they have optimized the surface roughness $\left(\mathrm{R}_{\mathrm{a}}\right.$ and $\left.\mathrm{R}_{\mathrm{t}} / \mathrm{R}_{\max }\right)$ [15].

In this study, a fuzzy reasoning of the multiple performance characteristics has been developed based on fuzzy logic. As a result, optimization of complicated multiple performance characteristics can be transformed into the optimization of a single multiperformance characteristics index (MPCI). In this paper an attempt is made to optimize the process parameters in turning GFRP composites with multiple performance characteristics has been investigated viz., Surface roughness $\left(R_{a}\right)$ and cutting force $\left(F_{z}\right)$.

\section{Materials and Methods}

The work material used for the present investigation is glass fiber reinforced plastics (GFRP) of different fiber orientation angles, whose angle vary from $30^{\circ} \sim 90^{\circ}$ in steps of $15^{\circ}$. The inner diameter of the tube is $30 \mathrm{~mm}$ and outer diameter $60 \mathrm{~mm}$ and length $500 \mathrm{~mm}$ respectively. The fiber orientation on the tubes has been set during the manufacture of tubes. The experiments are planned using Taguchi's $\mathrm{L}_{25}$ orthogonal array in the design of experiments (DoE), which helps in reducing the number of experiments. The cutting parameters considered in this investigation is cutting speed (V), feed (f), Depth of cut (d) and work piece (fiber orientation ' $\Phi$ ') in degrees. Since all the considered cutting parameters are multi-level variables and their outcome effects are not linearly related. The 
studies related to the GFRP composites indicated that the higher cutting conditions leads to high tool wear and poor surface finish [16]. The process parameter used and their levels chosen are given in Table 1.

Table 1. Process Parameters and Levels used for the Experimentation

\begin{tabular}{lccccccc}
\hline Process parameters & & & \multicolumn{5}{c}{ Levels } \\
With units & Notation & Variable & $\mathbf{1}$ & $\mathbf{2}$ & $\mathbf{3}$ & $\mathbf{4}$ & $\mathbf{5}$ \\
\hline Speed, $\mathrm{m} / \mathrm{min}$ & $\mathrm{V}$ & $\mathrm{x}_{1}$ & 40 & 60 & 95 & 145 & 225 \\
Feed, $\mathrm{mm} / \mathrm{rev}$ & $\mathrm{f}$ & $\mathrm{x}_{2}$ & 0.048 & 0.096 & 0.143 & 0.191 & 0.238 \\
Depth of cut, mm & $\mathrm{d}$ & $\mathrm{x}_{3}$ & 0.25 & 0.5 & 0.75 & 1.0 & 1.25 \\
$\begin{array}{l}\text { Fiber orientation } \\
\text { angle, deg }\end{array}$ & $\Phi$ & $\mathrm{x}_{4}$ & 30 & 45 & 60 & 75 & 90 \\
\hline
\end{tabular}

All the GFRP tubes are turned in a BHARAT all-geared lathe of model NAGMATI175 with a maximum speed of $1200 \mathrm{rpm}$ and power of $2.25 \mathrm{~kW}$. The ISO specification of the tool holder used for the turning operation is a WIDAX tool holder PC LNR $2020 \mathrm{~K} 12$ and the tool insert is cubic boron nitride (CBN) of type CNMA 120408. During machining, the cutting force developed was measured using a KISTLER quartz 3component dynamometer type 9257B. The dynamometer measures the active cutting force regardless of its application point. The dynamometer is connected to a 3-channel charge amplifier type 5807A through a connecting cable type 1687B5 this in turn is connected to the PC by a 37-pin cable from the A/D board. The dynamometer is calibrated for the cutting force in the range from 0 to $1000 \mathrm{~N}$. To get accuracy in measuring the cutting force, it is measured three times and average of cutting forces has been taken for analysis. The schematic layout of the original experimental setup is shown in Figure 1.

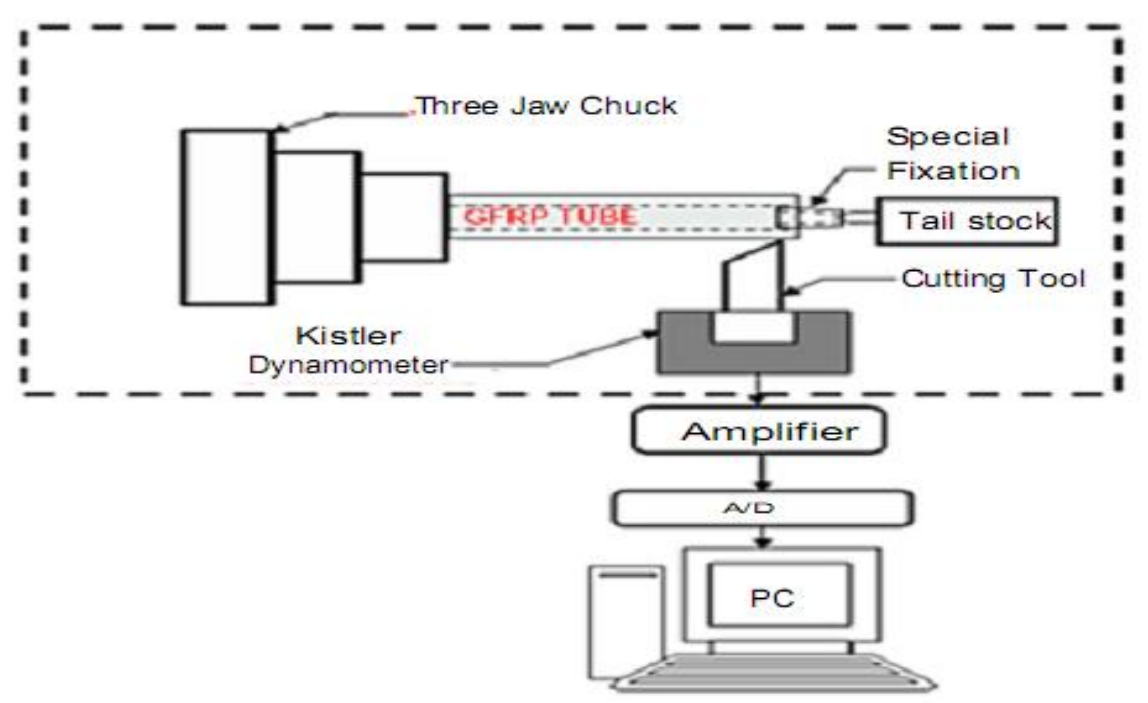

Figure 1. Schematic Layout of the Experimental Setup

\subsection{Optimization of Multiple Performance Characteristics with Fuzzy Logic}

Experimental design methods were developed originally by Fisher. However, classical experimental design methods are too complex and not easy to use. Furthermore, a large number of experiments have to be carried out as the number of the process parameters involved. To solve this, the Taguchi method uses a special design of orthogonal array to 
study the entire parameter space with only a small number of experiments. The experimental results are then transformed into a signal-to-noise $(\mathrm{S} / \mathrm{N})$ ratio. The $\mathrm{S} / \mathrm{N}$ ratio can be used to measure the deviation of the performance characteristics from the desired values. Usually, there are three categories of performance characteristics in the analysis of the S/N ratio the lower-the-better, the higher-the-better, and the nominal-the-better [17]. Regardless of the category of the performance characteristic, a larger $\mathrm{S} / \mathrm{N}$ ratio corresponds to better performance characteristic. Therefore, the optimal level of the process parameters is the level with the highest $\mathrm{S} / \mathrm{N}$ ratio. Furthermore, a statistical analysis of variance (ANOVA) is performed to identify the process parameters that are statistically significant. The optimal combination of the process parameters can then be predicted based on the above analysis. Finally, a confirmation experiment is conducted to verify the optimal process parameters obtained from the parameter design. In this paper, the use of fuzzy logic to deal with the optimization of a process with multiple performance characteristics is reported. First, several fuzzy rules are derived based on the performance requirement of the process. The loss function corresponding to each performance characteristic is fuzzified and then a single MPCI is obtained through fuzzy reasoning on the fuzzy rules. The MPCI can be used to optimize the process based on the Taguchi approach. In this investigation experimental data has been converted in to corresponding $\mathrm{S} / \mathrm{N}$ ratio using equation 1 . For surface roughness $\mathrm{R}_{\mathrm{a}}$, a Lower-the Better (LB) criterion and for the cutting force $\left(\mathrm{F}_{\mathrm{z}}\right)$, a Lower-the-Better $(\mathrm{HB})$ criterion has been selected.

The SN ratio with Lower-the-Better (LB) characteristics can be expressed as:

$$
\eta_{i j}=-10 \log \left(\frac{1}{n} \sum_{j=1}^{n} y_{i j}^{2}\right)
$$

The SN ratio with Higher-the-Better (HB) characteristics can be expressed as:

$$
\eta_{i j}=-10 \log \left(\frac{1}{n} \sum_{j=1}^{n} \frac{1}{Y_{i j}^{2}}\right)
$$

SN ratios have been normalized based on the Higher-the Better (HB) criterion, the normalization can be expressed as:

$$
x_{\mathrm{i}}=\frac{y i(k)-\min y i(k)}{\max y i(K)-\min y i(k)}
$$

Experimental data, corresponding S/N ratio, their normalized values and MPCI values are shown in Table 2.

Table 2. Experimental Data and MPCI

\begin{tabular}{|c|c|c|c|c|c|c|c|c|c|c|c|}
\hline Run & $\mathrm{V}$ & $\mathrm{f}$ & $\mathrm{d}$ & $\Phi$ & $\mathrm{Ra}$ & $\mathrm{F}_{\mathrm{z}}$ & \multicolumn{2}{|c|}{$\mathrm{S} / \mathrm{N}$ ration } & \multicolumn{2}{|c|}{ Normalized } & \\
\cline { 8 - 11 } & & & & & & & $\mathrm{R}_{\mathrm{a}}$ & $\mathrm{F}_{\mathrm{z}}$ & $\mathrm{R}_{\mathrm{a}}$ & $\mathrm{F}_{\mathrm{z}}$ & MPCI \\
\hline 1 & 40 & 0.048 & 0.25 & 30 & 3.0582 & 346.88 & -9.703 & -50.80 & 0.5334 & 0.8171 & 0.686 \\
\hline 2 & 40 & 0.096 & 0.5 & 45 & 3.5757 & 385.19 & -11.06 & -51.71 & 0.347 & 0.6454 & 0.625 \\
\hline 3 & 40 & 0.143 & 0.75 & 60 & 3.6219 & 436.51 & -11.18 & -52.8 & 0.2943 & 0.4404 & 0.556 \\
\hline 4 & 40 & 0.191 & 1.0 & 75 & 4.1052 & 544.74 & -12.27 & -54.72 & 0.0951 & 0.0774 & 0.0894 \\
\hline 5 & 40 & 0.238 & 1.25 & 90 & 4.3582 & 571.11 & -12.78 & -55.13 & 0.00 & 0.00 & 0.08 \\
\hline 6 & 60 & 0.048 & 0.5 & 60 & 3.4071 & 350.95 & -10.65 & -50.90 & 0.3915 & 0.7929 & 0.638 \\
\hline 7 & 60 & 0.096 & 0.75 & 75 & 3.5395 & 381.69 & -10.98 & -51.63 & 0.3309 & 0.6604 & 0.625 \\
\hline 8 & 60 & 0.143 & 1.0 & 90 & 3.7903 & 424.62 & -11.57 & -52.56 & 0.222 & 0.4857 & .401 \\
\hline 9 & 60 & 0.191 & 1.25 & 30 & 3.6903 & 394.92 & -11.34 & -51.93 & 0.2646 & 0.0045 & 0.609 \\
\hline 10 & 60 & 0.238 & .25 & 45 & 3.9857 & 401.32 & -12.01 & -52.07 & 0.1421 & 0.5782 & 0.479 \\
\hline 11 & 95 & 0.048 & 0.75 & 90 & 2.8993 & 365.94 & -9.25 & -51.27 & 0.6482 & 0.7294 & 0.625 \\
\hline
\end{tabular}




\begin{tabular}{|c|c|c|c|c|c|c|c|c|c|c|c|}
\hline 12 & 95 & 0.096 & 1.0 & 30 & 2.666 & 326.98 & -8.52 & -50.29 & 0.7816 & 0.9139 & 0.69 \\
\hline 13 & 95 & 0.143 & 1.25 & 45 & 3.3441 & 369.48 & -10.48 & -51.35 & 0.4212 & 0.7136 & 0.663 \\
\hline 14 & 95 & 0.191 & 0.25 & 60 & 3.7221 & 385.17 & -11.42 & -51.71 & 0.2509 & 0.6455 & 0.625 \\
\hline 15 & 95 & 0.238 & 0.5 & 75 & 3.9812 & 445.06 & -12.00 & -52.96 & 0.1438 & 0.4086 & 0.39 \\
\hline 16 & 145 & 0.048 & 1.0 & 45 & 2.324 & 310.25 & -7.32 & -49.83 & 1.00 & 1.00 & 0.92 \\
\hline 17 & 145 & 0.096 & 1.25 & 60 & 2.7831 & 313.78 & -8.89 & -49.93 & 0.7133 & 0.9814 & 0.808 \\
\hline 18 & 145 & 0.143 & 0.25 & 75 & 3.3674 & 376.18 & -10.34 & -51.50 & 0.4102 & 0.6842 & 0.654 \\
\hline 19 & 145 & 0.191 & 0.5 & 90 & 3.5476 & 445.7 & -10.99 & -52.98 & 0.3273 & 0.4063 & 0.589 \\
\hline 20 & 145 & 0.238 & 0.75 & 30 & 2.9543 & 384.71 & -.941 & -51.70 & 0.6183 & 0.6474 & 0.63 \\
\hline 21 & 225 & 0.048 & 1.25 & 75 & 2.523 & 341.98 & -8.64 & -50.68 & 0.8693 & 0.8404 & 0.643 \\
\hline 22 & 225 & 0.096 & 0.25 & 90 & 3.4394 & 393.49 & -10.73 & -51.89 & 0.3765 & 0.6105 & 0.625 \\
\hline 23 & 225 & 0.143 & 0.5 & 30 & 3.1356 & 328.69 & -9.92 & -50.33 & 0.5236 & 0.9053 & 0.716 \\
\hline 24 & 225 & 0.191 & 0.75 & 45 & 3.231 & 363.26 & -10.18 & -51.20 & 0.4759 & 0.7415 & 0.722 \\
\hline 25 & 225 & 0.238 & 1.0 & 60 & 3.3285 & 432.04 & -10.44 & -52.71 & 0.4286 & 0.4573 & 0.625 \\
\hline
\end{tabular}

\section{Fuzzy Logic System}

Fuzzy logic has rapidly become one of the most successful of today's technologies for developing sophisticated control systems. Fuzzy logic (FL) has been used in many practical engineering situations because of its capability in dealing with imprecise and inexact information. The powerful aspect of fuzzy logic is that, it mimics the human decision making with an ability to generate precise solutions from certain or approximate information. The combination of incomplete, imprecise information and the imprecise nature of the decision-making process make fuzzy logic very effective in modeling complex engineering, business, finance and management systems which are otherwise difficult to model. Fuzzy systems make its decisions on inputs and outputs in the form of linguistic variables. The variables are tested with IF-THEN rules, which produce one or more responses depending on which rules they are asserted. The response of each rule is weighed according to the degree of membership of its inputs and the centroid of the responses is calculated to generate the appropriate output [18]. Figure 2 shows the fuzzy inference system, it is also known as fuzzy rule based system. Fuzzy logic system comprises of a fuzzifier, membership function, a fuzzy rule base, an inference engine and defuzzifier. The fuzzifier uses membership function to fuzzyfy $\mathrm{S} / \mathrm{N}$ ratios of each performance characteristic. Next the inference engine (Mamdani fuzzy inference sytem) performs fuzzy reasoning on fuzzy rules to generate a fuzzy value. Finally, the defuzzifier converts fuzzy predicted value into a Multi Performance Characteristic Index (MPCI) response can be used to find the better accuracy of output of the MPCI in turning of GFRP composites with CBN tool.

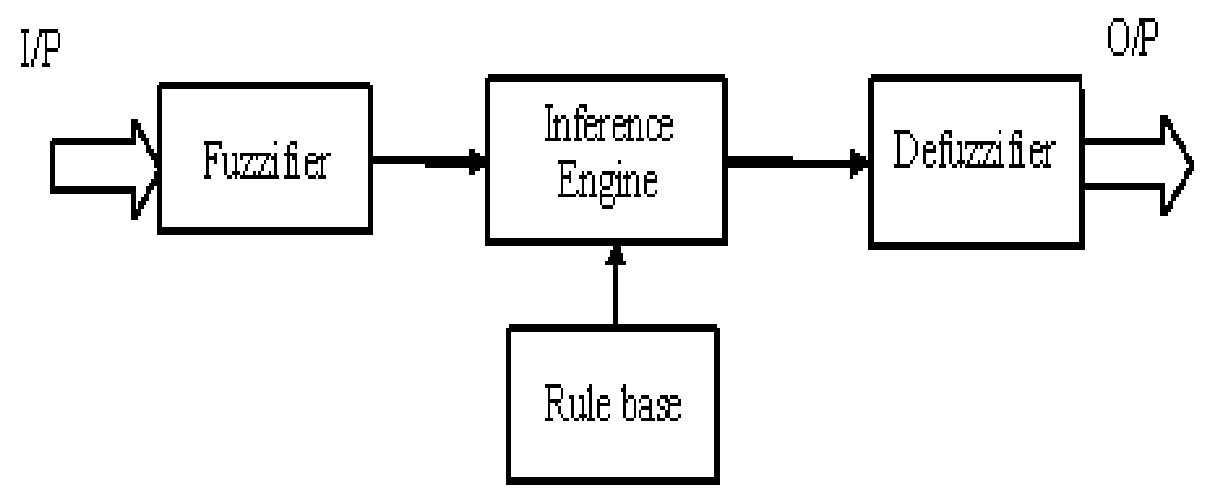

Figure 2. Fuzzy Inference System 
In calculating MPCI in FIS system, various membership functions (MFs) have been assigned to the input variables i.e., normalized $\mathrm{S} / \mathrm{N}$ ration of surface roughness $\left(\mathrm{R}_{\mathrm{a}}\right)$ and normalized $\mathrm{S} / \mathrm{N}$ ration of cutting force $\left(\mathrm{F}_{\mathrm{z}}\right)$. The membership functions selected for input variables are "Low", "Low Medium", "Medium", "High Medium", and "High" as shown in Figure 3-4. Five membership functions have been selected for the output i.e., MPCI: "Very small" "Small", "Medium", "Large", "Very Large" as shown in Figure 5.

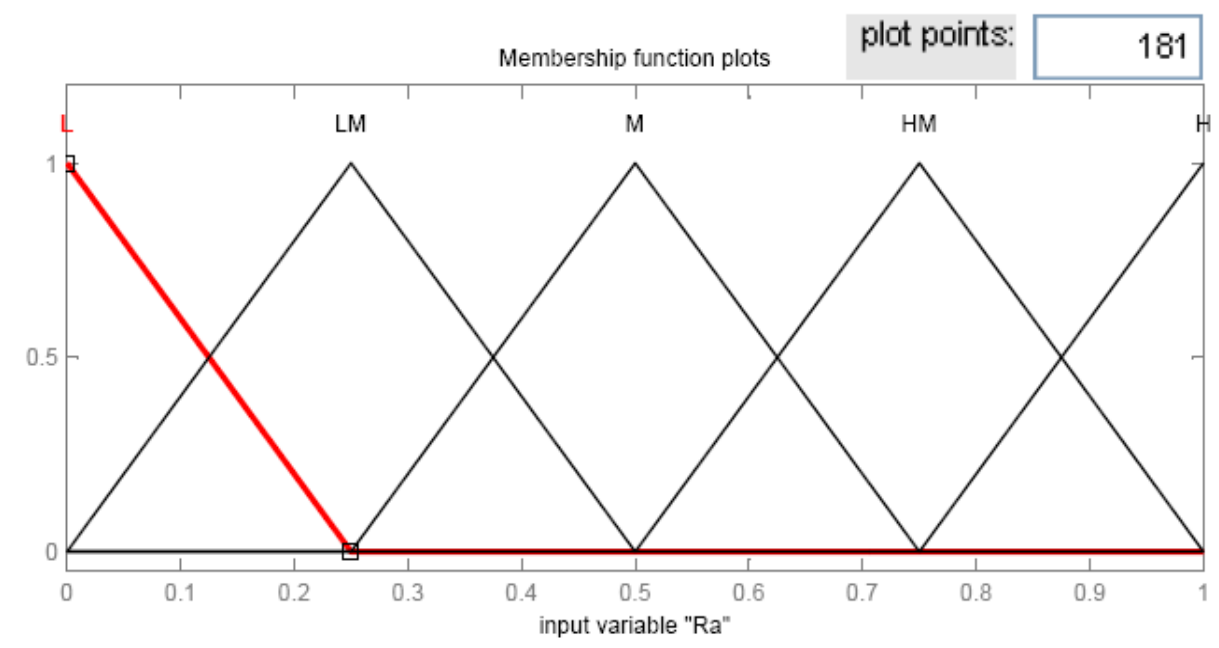

Figure 3. Membership Functions for $R_{a}$ (Normalized $S / N$ ratio for $R_{a}$ )

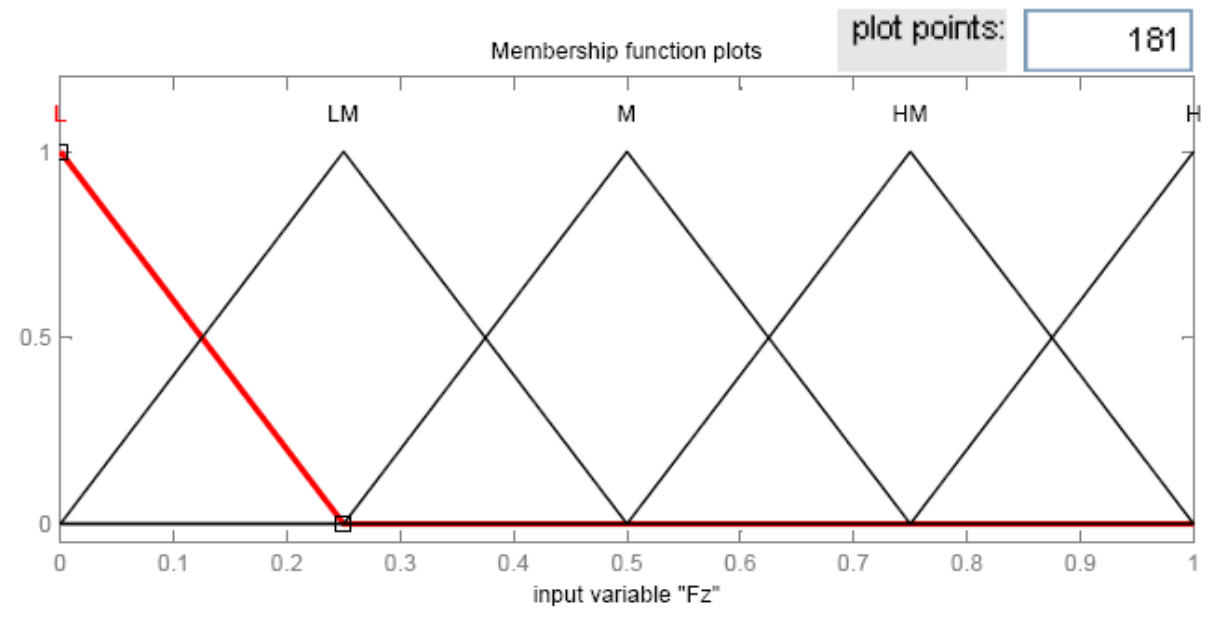

Figure 4. Membership Functions for $F_{z}$ (Normalized $S / N$ Ratio for $F_{z}$ ) 


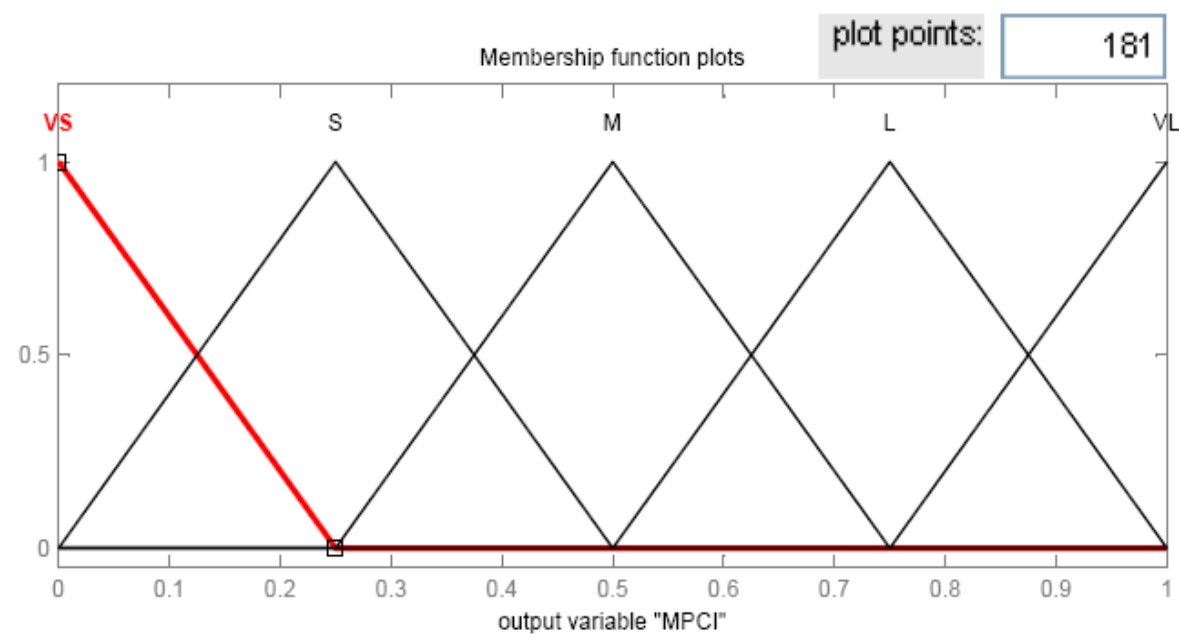

Figure 5. Membership Functions for MPCI

\section{Results and Discussions}

Glass fiber reinforced plastics (GFRP) composite materials are a feasible alternative to engineering materials. They have excellent properties and are being extensively used in variety of engineering applications. However, the users of FRP are facing difficulties to machine it, because of its anisotropic properties. When GFRP composites are machined, discontinuous chips in powder form are produced, which is entirely different from machining of metals. The machining of GFRP composites differ from machining of metals, due to this fact optimization of multiple performances is difficult in machining of GFRP Composites. In this investigation fuzzy logic combined with Taguchi method was employed for the optimization of multiple performance characteristics viz., Surface roughness $\left(\mathrm{R}_{\mathrm{a}}\right)$ and Cutting force $\left(\mathrm{F}_{\mathrm{z}}\right)$ in turning of GFRP composites with CBN Tool insert.

\subsection{MPCI Optimal Process Parameters for Turning of GFRP Composites}

The normalized $\mathrm{S} / \mathrm{N}$ ratio for surface roughness $\left(\mathrm{R}_{\mathrm{a}}\right)$ and cutting force $\left(\mathrm{F}_{\mathrm{z}}\right)$ are taken as input variables. Table 2 shows the MPCI values acquired from the fuzzy logic system constructed in the previous section. A Figure 6 show the effect plot for MPCI, larger is the MPCI smaller is the variance of the performance characteristic around the desired value. However, the relative importance amongst the machining parameters for the multiple characteristics still needs to be known so that the optimal combination of the machining parameters can be determined more accurately. Based on the results shown in Figure 6, the optimal combination of process parameters in turning of GFRP composite is determined. The following parameter settings have been identified to yield the best results: Cutting speed $(\mathrm{V})=145 \mathrm{~m} / \mathrm{min}$, feed $(\mathrm{f})=0.048 \mathrm{~mm} / \mathrm{rev}$, Depth of cut $(\mathrm{d})=$ $0.75 \mathrm{~mm}$ and fiber orientation angle $(\Phi)=45^{\circ}$. 


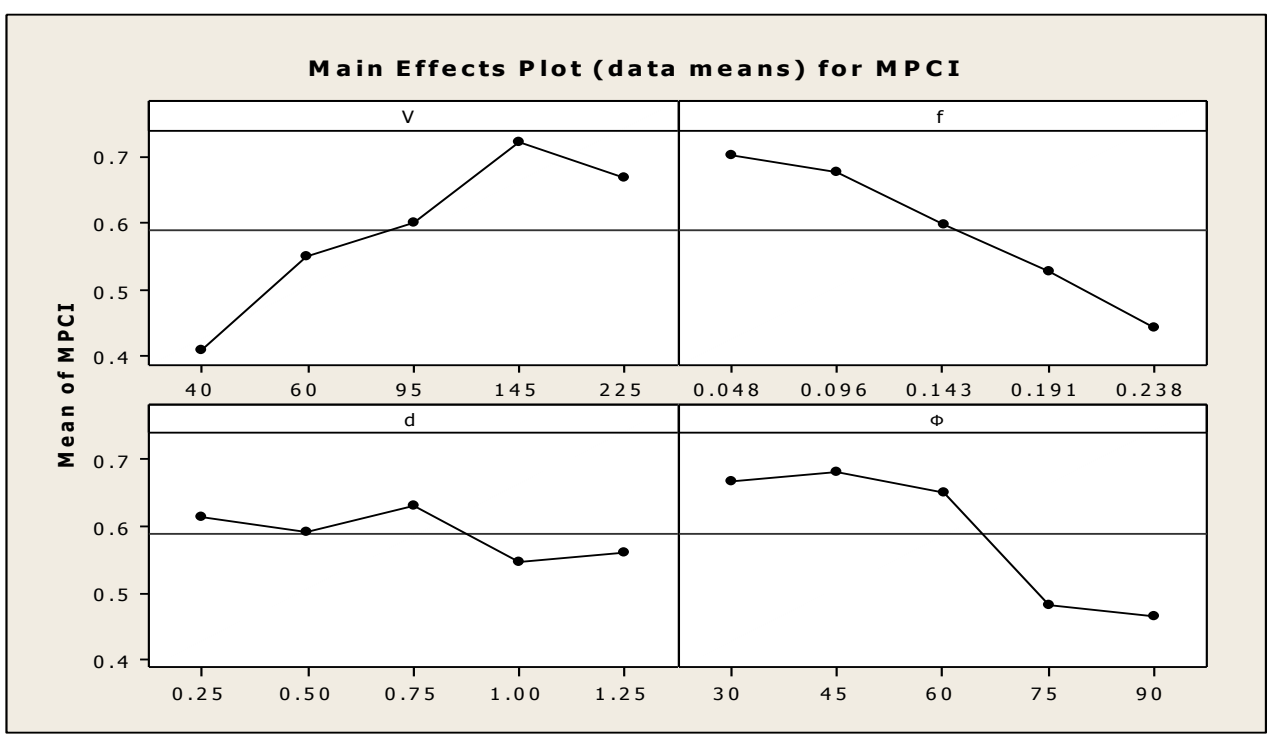

Figure 6. Main Effect Plots for MPCl

\subsection{Analysis of Variance}

The purpose of the ANOVA is to investigate which process parameter significantly affects the performance characteristics. This is accomplished by separating the total variability of the multi-performance characteristic index (MPCI), which is measured by the sum of the squared deviation from the total mean of the MPCI, into contribution by each of the process parameter and the error. The F-test determines which process parameter has a significant effect on the performance characteristic. Usually, the change of the process parameter has a significant effect on the performance characteristic when the $\mathrm{F}$ value is large. The Table 3 shows the analysis of variance for MPCI, from that table it is inferred that the cutting speed (V), Feed (f) and fiber orientation angle $(\Phi)$ are the significant parameters affecting the multiple performance characteristics.

Table 3. Analysis of Variance for MPCl

\begin{tabular}{|c|c|r|r|c|c|}
\hline Source & DF & SeqSS & AdjMS & F & \% contribution \\
\hline $\mathrm{V}$ & 4 & 0.288882 & 0.072221 & 9.87 & 34.69 \\
\hline $\mathrm{f}$ & 4 & 0.230445 & 0.57611 & 7.88 & 27.67 \\
\hline $\mathrm{d}$ & 4 & 0.025855 & 0.006464 & 0.88 & 3.10 \\
\hline$\Phi$ & 4 & 0.228928 & 0.057232 & 7.82 & 27.49 \\
\hline Error & 8 & 0.058524 & 0.007316 & & 7.02 \\
\hline Total & 24 & 0.832635 & & & 100 \\
\hline
\end{tabular}

\section{Conclusions}

The present study deals with the investigation on some aspects of machinability such as surface roughness and cutting force in turning of GFRP composite materials for the range of fiber orientation angle $\left(30^{\circ} \sim 90^{\circ}\right)$ with CBN cutting tool insert. Based on the experimental results the following conclusions are drawn within the parameters selected.

The optimal combination of process parameters for the MPCI are: cutting speed (V) $=145 \mathrm{~m} / \mathrm{min}$, feed $(\mathrm{f})=0.048 \mathrm{~mm} / \mathrm{rev}$, Depth of cut $(\mathrm{d})=0.75 \mathrm{~mm}$, Fiber orientation angle $(\Phi)=45^{\circ}$. 
Based on ANOVA results, the process parameters most significantly influencing the MPCI are cutting speed (V), feed (f) and fiber orientation angle $(\Phi)$.

Combining the Taguchi method and fuzzy logic facilitates simultaneous acquisition of low surface roughness $\left(\mathrm{R}_{\mathrm{a}}\right)$ and low cutting force $\left(\mathrm{F}_{\mathrm{z}}\right)$ in machining GFRP Composites.

\section{Acknowledgement}

Authors are thankful to the Hon'ble Charman Dr. M. Santhiramudu for providing all institutional help to carry out this research work.

\section{References}

[1] W. König, C. Wulf, P. Grab and H. Willerscheid, "A theory of machining of fiber reinforced plastics", CIRP Annals-Manufacturing Technology, vol. 34, no. 2, (1985), pp. 537-548.

[2] A. Koplev, A. Lystrup and T. Vorm, "The cutting process, chips and cutting forces in CFRP", Compositesvol, vol. 14, no. 4, (1983), pp. 371-376.

[3] K. Sakuma and M. Seto, "Tool wear in cutting glass-fibre-reinforced-plastics (the relation between fibre orientation and tool wear)", Bulletin of the JSME, vol. 26, no. 218, (1983), pp. 1420-1427.

[4] N. Bhatnagar, N. Ramakrishnan, N. K. Naik and R. Komandurai, "On the machining of fiber Reinforced plastics (FRP) composite laminates”, Int. J.Machine Tool Manuf, vol. 35, no. 5, (1995), pp. 701-716.

[5] G. Santhanakrishnan, R. Krishnamurthy and S. K. Malhotra, "High-speed steel tool wear studies in machiningof glass-fiber reinforced plastics", wear, vol. 132, no. 2, (1989), pp. 327-336.

[6] M. Ramulu, D. Arola and K. Colligan, "Preliminary Investigation on the Surface Integrity of fiberReinforced Plastics", Engineering systems Design and Analysis, ASME, vol. 64, no. 2, (1994), pp. 93-101.

[7] H. Tekeyama and N. Lijima, "Machinability of Glass fiber Reinforced plastics and application of ultrasonic marching", Annals of the CIR, vol. 37, no. 1, (1998), pp. 93-96.

[8] J. P. Davim and F. Mata, "Influence of cutting parameters on surface roughness using statistical analysis", Industrial Lubrication Tribology, vol. 56, no. 5, (2004), pp. 270-274.

[9] S.-Ook., E.-S. Lee and S. L. A. Noh, "Study on the Cutting Characteristics of Glass Fiber Reinforced Plastics with Respect to Tool Materials and Geometries", Journal of Materials Processing Technology vol. 68 , no. 1, (1997), pp. 60-67.

[10] D. H. Wang, M. Ramulu and D. Arola, "Orthogonal Cutting Mechanisms of Graphite Epoxy Composites: Part I: Unidirectional Laminate", International Journal of Machine Tools Manufacturing, vol. 35, no. 2, (1995), pp. 1639-1648.

[11] J. Parm, "A study on the effects of PCD tool geometry on the machining of graphite epoxy composite Material", Dissertation, Univ. Washington, (1991).

[12] K. Palani Kumar, "Cutting parameters optimization for surface roughness in turning of GFRP composites using Taguchi's method", Journal of Reinforced Plastics and Composites, vol. 25, no. 16, (2006), pp. 1739-1751.

[13] R. Kumar Verma, K. Abhishek and S. Datta, "Fuzzy rule based Optimization in machining of FRP composites", Turkish Journal of Fuzzy systems, vol. 2, no. 2, (2011), pp. 99-121.

[14] J. P. Davim and F. Mata, "Optimization of surface roughness on turning fibre-reinforced plastics (FRPs) with diamond cutting tools", International Journal of Advanced Manufacturing Technology, vol. 26, no. 4, (2005), pp. 319-323.

[15] K. Palanikumar, L. Karunamoorthy, R. Karthikeyan and B. Latha, "Optimization of machining parameters in turning GFRP composites using a carbide (K10) tool based on the Taguchi method with fuzzy logics", Metals and Materials International, vol. 12, no. 6, (2006), pp. 483-491.

[16] Puri and Deshpande, "Simultaneous optimization of multiple quality characteristics of WEDM based on fuzzy logic and Taguchi technique", Proceedings of the Fifth Asia Pacific Industrial Engineering and Management Systems Conference, (2004).

[17] L. Zadeh, "Fuzzy sets", International Journal of Information and Control, vol. 8, (1965), pp. 338-353.

[18] O. Yilmaz, O. Eyercioglu and N. N. Z, Gindy, "A user-friendly fuzzy- based system for the selection of electro discharge machining process parameters", Journal of Materials Processing, Technology, vol. 172, no. 3, (2006), pp. 363-371.

\section{Authors}

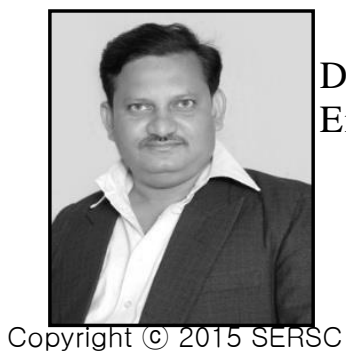

Dr. Syed Altaf Hussain, working as a Professor in the Department of Mechanical Engineering, RGM College of Engineering \& Technology, Nandyal-518501, (A.P), India.. He 
obtained Ph.D degree from JNT University, Anantapur, A.P, India. He has more than 17 years of experience in teaching. His current area of research includes Machining of composite materials, Finite Element Analysis, Optimization, Simulation and Modeling.

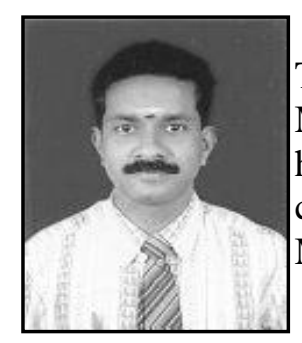

Dr. K. Palanikumar is a Principal, Sri Sairam Institute of Technology, Chennai-44, India. He obtained Ph.D degree in Mechanical Engineering from Anna University, Chennai, India. He has more than 20 years of experience in teaching and research. His current area of research includes Machining of composite materials, Modern manufacturing, Optimization, Simulation and Modeling.

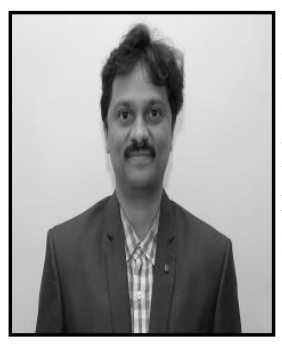

Dr. A. Gopala Krishna is Professor in Department of Mechanical Engineering, JNTU Kakinada. He is actively involved in research. To testify that, ten Ph.D. scholars have been awarded their degrees under his guidance and has published papers crossing one hundred in reputed journals and conferences. His papers possess high citation indices. His areas of research are machining, welding, metal forming and finite element modeling. 